\title{
Inhibition of the CyclinD1 promoter in response to sonic hedgehog signaling pathway transduction is mediated by Gli1
}

\author{
ZHONGXIAO LIN ${ }^{1}$, HANSONG SHENG ${ }^{1}$, CHAOGUO YOU $^{1}$, MING CAI $^{1}$, YIPING ZHANG ${ }^{1}$, \\ LI SHENG YU ${ }^{1}$, XIAOMING YU ${ }^{2}$, JIAN LIN ${ }^{1 *}$ and NU ZHANG ${ }^{1 *}$ \\ Departments of ${ }^{1}$ Neurosurgery and ${ }^{2}$ Neonatology, The Second Affiliated Hospital and Yuying Children's Hospital of \\ Wenzhou Medical University, Wenzhou, Zhejiang 325000, P.R. China
}

Received September 23, 2015; Accepted October 21, 2016

DOI: $10.3892 / \mathrm{etm} .2016 .3969$

\begin{abstract}
Medulloblastoma (MB) is the most common malignant tumor of the central nervous system in children. Accumulating evidence suggests a major role for the activation of the sonic hedgehog ( $\mathrm{SHH}$ ) signaling pathway in the development of MB cells; however, the mechanisms underlying the effect of this pathway on tumor survival and growth remain poorly understood. The Gli family zinc finger 1 (Gli1) transcription factor is considered as a mediator of the SHH signaling pathway in MB cells. Therefore, the present study investigated whether the $\mathrm{SHH}$ signaling pathway promotes the apoptosis of MB cells via downregulation of Gli1. GANT61, a novel Gli1 inhibitor, is known to have an in vitro activity against tumors. In the current study, Daoy cells were treated with different concentrations of GANT61 for $24 \mathrm{~h}$, and the effect on cell proliferation was assayed by cell counting kit- 8 assay. In addition, the cell cycle progression and apoptosis were assayed by flow cytometry analysis and hematoxylin-eosin (HE) staining. The effects of GANT61 treatment on SHH signaling pathway at the mRNA level were assayed by polymerase chain reaction (PCR). To further elucidate the inhibitory effects of GANT61 on the expression of Gli1 and CyclinD1, their protein levels were examined by western blot and immunofluorescence. The results indicated that GANT61 significantly inhibited the proliferation of Daoy cells in a dose-dependent manner, compared with the control group $(\mathrm{P}<0.05)$. HE staining revealed that cells had increasingly abnormal protuberance with increasing GANT61
\end{abstract}

Correspondence to: Professor Nu Zhang or Professor Jian Lin, Department of Neurosurgery, The Second Affiliated Hospital and Yuying Children's Hospital of Wenzhou Medical University, 109 Xueyuanxi Road, Wenzhou, Zhejiang 325000, P.R. China

E-mail: zhangnu65@hotmail.com; 371988079@qq.com

E-mail: linjian3222@126.com

*Contributed equally

Key words: medulloblastoma, sonic hedgehog signaling pathway, GANT61, Gli family zinc finger 1, CyclinD1 concentration. Flow cytometry analysis also demonstrated that GANT61 induced G1/S arrest and apoptosis of Daoy cells in a dose-dependent manner $(\mathrm{P}<0.05)$. Gli1 and CyclinD1 mRNA expression levels were downregulated by GANT61 treatment $(\mathrm{P}<0.05)$; similarly, their protein levels were downregulated by GANT61 treatment in a dose-dependent manner $(\mathrm{P}<0.05)$. In conclusion, Gli1 expression was significantly associated with CyclinD1 expression in MB. These data demonstrated that Gli1 is an important mediator of the SHH pathway activity in $\mathrm{MB}$, and may be a novel agent for use in combined chemotherapeutic regimens.

\section{Introduction}

Medulloblastoma (MB) is the most common pediatric malignant brain tumor, and has a poor clinical outcome $(1,2)$. With currently available multimodality therapies, including surgery, radiotherapy and chemotherapy, numerous children have a favorable prognosis; however, the majority of patients suffer from considerable long-term disabilities and morbidity following aggressive multimodal therapy (3-5). Attempts to further improve the outcomes have been restricted by the cytotoxicity of conventional medication and the nature of the disease. Therefore, an increased understanding of the mechanisms underlying MB is crucial in the development of novel therapeutic approaches.

Aberrant activation of the sonic hedgehog (SHH) signaling pathway has been implicated in the development of MB (6-8). The Gli family zinc finger 1 (Gli1) transcription factor is considered to be a mediator of the SHH signaling pathway in $\mathrm{MB}$, although its tumorigenic nature and its relative contribution to tumorigenesis remain poorly understood (9).

CyclinD1 is a key protein in the cyclin family that regulates the G1/S transition and is highly expressed in multiple types of tumors $(10,11)$. This protein is regulated by a complex system of signal transduction pathways $(12,13)$. CyclinD1 expression is known to be regulated by Gli1 in MB. Furthermore, GANT61 is a specific Gli1 inhibitor, which has been shown to inhibit the DNA binding activity of Gli1 by binding to the zinc-finger domain (14-16).

In order to examine the role of Gli1 in MB, our previous studies screened for genes preferentially regulated by Gli1 in MB cells $(17,18)$. CyclinD1 plays important role in tumor 
proliferation, and thus the expression of CyclinD1 was investigated in MB cells.

\section{Materials and methods}

Reagents and antibodies. GANT61 (Sigma-Aldrich; Merck KGaA, Darmstadt, Germany) was dissolved in dimethyl sulfoxide (DMSO) and stored at $-20^{\circ} \mathrm{C}$ until required for use. The final DMSO concentration in all cultures, including the vehicle control groups, was $0.1 \%$ in RPMI 1640 medium (Gibco; Thermo Fisher Scientific, Inc., Grand Island, NY, USA). Fetal bovine serum (FBS) and $0.25 \%$ trypsin/EDTA were purchased from Gibco (Thermo Fisher Scientific, Inc.). The hematoxylin and eosin (HE) staining kit (G1060) was purchased from SuoLaibao Technology Co., Ltd. (Beijing, China), and the FITC-Annexin V kit from Abcam (ab14150; Cambridge, MA, USA). The cell counting kit-8 (CCK-8) assay for cell proliferation analysis was purchased from Dojindo Chemical Research Institute (Tokyo, Japan), while the PrimeScript RT Master Mix and reverse transcription (RT) kit (RR014A) was obtained from Takara Bio, Inc. (Shiga, Japan; PrimeScript RT Master Mix). In addition, SYBR Green I was purchased from Beijing Noble Ryder Technology Co., Ltd. (Beijing, China). Antibodies against Gli1 (ab49314) and CyclinD1 (ab187364) were acquired from Abcam, while $\beta$-actin antibody (AP0060) was purchased from Bioworld Technology, Inc. (Louis Park, MN, USA). The secondary antibody of Gli1 (BL003A) and CyclinD1 (BL001A) were acquired from Biosharp (Wuhan, China) (19).

Cell culture. Daoy, an MB cell line, was purchased from ATCC (Manassas, VA, USA). The Daoy cells were maintained in RPMI 1640 medium supplemented with $10 \%$ fetal bovine serum (500 ml; Gibco), $100 \mu \mathrm{g} / \mathrm{ml}$ penicillin and $100 \mu \mathrm{g} / \mathrm{ml}$ streptomycin (Invitrogen; Thermo Fisher Scientific, Inc., Carlsbad, CA, USA) at $37^{\circ} \mathrm{C}$ with $5 \% \mathrm{CO}_{2}$. Prior to each experiment, trypan blue staining (Sigma-Aldrich) was used to define the cell vitality. The cell activity was determined to be $>98 \%$.

Cell proliferation analysis. CCK-8 assay was performed to investigate the cell proliferation, according to the manufacturer's instructions of the kit. Briefly, Daoy cells in exponential growth phase were pipetted into single cells following trypsin digestion. Cells were seeded in a 96-well plate at a density of $8 \times 10^{3}$ cells/well. RPMI 1640 medium containing 10\% FBS was used to culture the cells for $24 \mathrm{~h}$ prior to replacing with serum-free medium. Next, the cells were starved for $6 \mathrm{~h}$ and then incubated in RPMI 1640 medium supplemented with $1 \%$ FBS. The cell culture groups included three groups treated with different concentrations of GANT61 (10, 20 and $40 \mu \mathrm{M})$ and a negative untreated control group with normal growing cells, while wells with no cells acted as the blank control. A total of six replicates per group were investigated. The cells were continually cultured in the incubator for a further $24 \mathrm{~h}$ before the culture medium was discarded. Subsequently, $100 \mu \mathrm{l}$ fresh RPMI 1640 medium and $10 \mu$ l CCK-8 solution were added into each well. The cells were placed in the incubator to avoid light exposure, and the absorbance at $450 \mathrm{~nm}$ $\left(\mathrm{A}_{450}\right)$ was measured at $0.5,1,2$ and $4 \mathrm{~h}$, with a Bio-Rad 680 microplate reader (Bio-Rad Laboratories, Inc., Hercules, CA, USA).. The proliferation inhibition rate was calculated as follows: Proliferation inhibition $(\%)=\left[\mathrm{A}_{450}\right.$ (negative control group) - $\mathrm{A}_{450}$ (GANT61-treated group)] / $\mathrm{A}_{450}$ (negative control group) $\times 100 \%$.

HE staining. Daoy cells in the exponential growth phase were digested into a concentration of $1 \times 10^{6}$ cells $/ \mathrm{ml}$, added to glass coverslips and cultured for $24 \mathrm{~h}$ in an incubator. The medium was replaced, followed by addition of different concentrations of GANT61 (10, 20 and $40 \mu \mathrm{M})$, while the group without GANT61 treatment served as the control. Subsequently, the cells were extracted after culturing for $24 \mathrm{~h}$, washed with phosphate-buffered saline (PBS) for three times and fixed in 4\% paraformaldehyde for $60 \mathrm{~min}$, followed by washing three times with PBS. The cells were then stained with hematoxylin for $5 \mathrm{~min}$ and washed by tap water. Following incubation in differentiation buffer for a few seconds and washing with water, eosin was added for $10 \mathrm{~min}$. After washing with tap water, the stained sample was dehydrated, sealed and prepared for microscopic observation.

Flow cytometry. In order to investigate the cell cycle progression, flow cytometry analysis was performed using the FITC-Annexin V kit, according to the manufacturer's instructions. Briefly, $2 \times 10^{4}$ cells were transferred into $10-\mathrm{ml}$ centrifuge tubes, and centrifuged for $5 \mathrm{~min}$ at 250-500 $\mathrm{x} g$ at $4^{\circ} \mathrm{C}$. After the culture medium was discarded, cells were washed once with the binding buffer and centrifuged for $5 \mathrm{~min}$ at at $250-500 \times g$ at $4^{\circ} \mathrm{C}$. The final concentration of $1 \mu \mathrm{g} / \mathrm{ml}$ propidium iodide (PI) with FITC-Annexin V (included in the kit) was dissolved in incubation buffer. Resuspended cells were labeled in the dark for 10-15 min with $100 \mu$ l solution buffer at room temperature. Cells were then precipitated by centrifugation at at $250-500 \mathrm{xg}$ at $4^{\circ} \mathrm{C}$ for $5 \mathrm{~min}$ and washed with incubation buffer. The sample was then incubated at the $4^{\circ} \mathrm{C}$ for $20 \mathrm{~min}$ in the dark without vibration. Detection and quantification of apoptotic cells was obtained by flow cytometry. This test was performed according to the manufacturer's instructions

RT-polymerase chain reaction (PCR) array analysis. Daoy cells were seeded in RPMI 1640 medium supplemented with $10 \%$ FBS, followed by exposure to different concentrations of GANT61 for $24 \mathrm{~h}$, while the control was not treated with any GANT61. Total RNA was extracted from the cells with TRIzol reagent (Invitrogen; Thermo Fisher Scientific, Inc.) after $24 \mathrm{~h}$, according to the manufacturer's instructions. The total RNA extracted was then treated with the PrimeScript RT Master Mix for removal of contaminating DNA and for reverse transcription into cDNA. Briefly, Primers specific for each of the signaling molecules were designed using NCBI/Primer-BLAST and used to generate the PCR products. The following primers were used: GLI1-Forward: 5'-GGG AGGAAAGCAGACTGACT-3'; GLI1-Reverse: 5'-TGGAGA GGTCTTCAGTGCTG-3'; CyclinD1-Forward: 5'-GCATGT TCGTGGCCTCTAAG-3'; CyclinD1-Reverse: 5'-CGTGTT TGCGGATGATCTGT-3'; GAPDH-Forward: 5'-CTCTCT GCTCCTCCCTGTTC-3'; GAPDH-Reverse: 5'-CAATCT CCACTTTGCCACTGC-3'. Target sequences were amplified 


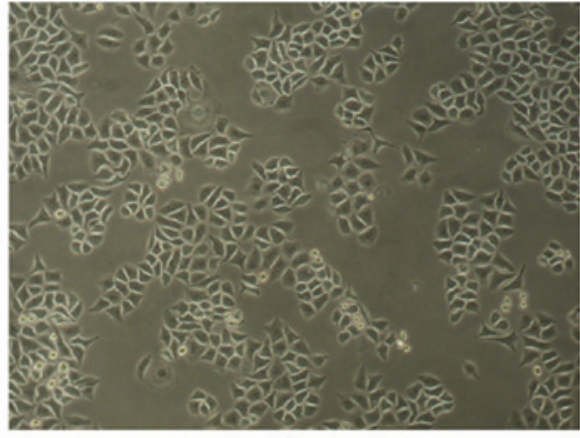

$0 \mu \mathrm{M}$

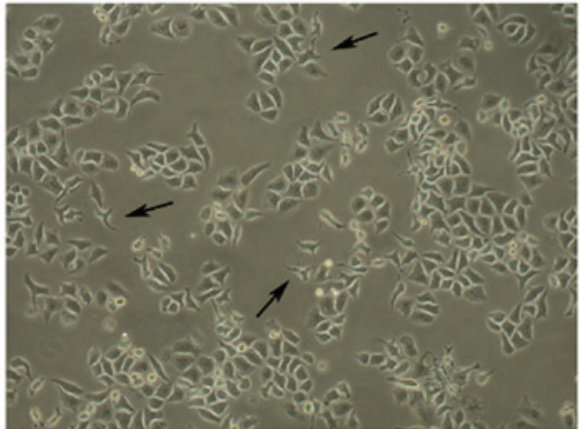

$20 \mu \mathrm{M}$

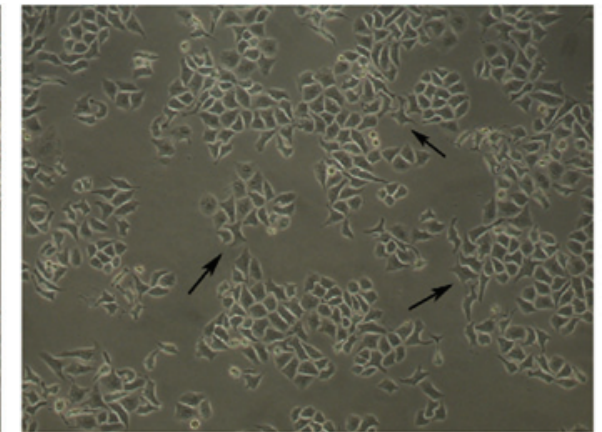

$10 \mu \mathrm{M}$

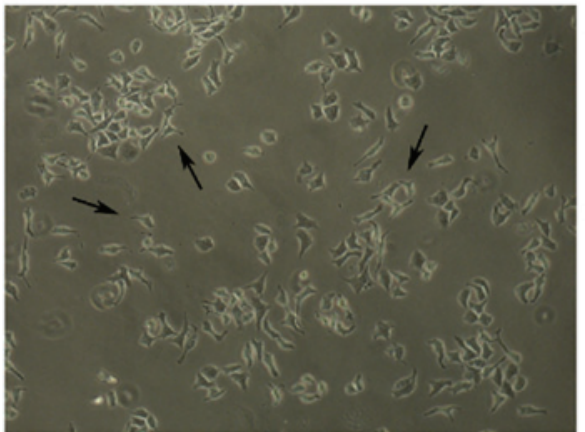

$40 \mu \mathrm{M}$

Figure 1. Morphological changes of GANT61-treated Daoy cells, as observed by inverted microscopy (magnification, x100). Normal adherent cells were intercellular tight, and their shapes were rectangular or triangular. However, Daoy cell groups treated with increasing concentrations of GANT61 demonstrated an evidently decreased number of cells, morphological changes and diversity.

at $95^{\circ} \mathrm{C}$ for $1 \mathrm{~min}$, followed by 40 cycles of $95^{\circ} \mathrm{C}$ for $5 \mathrm{sec}$ and $60^{\circ} \mathrm{C}$ for $30 \mathrm{sec}$. GAPDH was used as endogenous normalization control. Subsequently, the samples were investigated by PCR array. Data were analyzed by the $\Delta \Delta \mathrm{Cq}$ method to determine the mRNA expression levels, as previously described $(20,21)$. The experiment was performed in triplicate and repeated three times.

Western blot analysis. Daoy cells were synchronized in RPMI 1640 medium with 10\% FBS, followed by exposure to different concentrations of GANT61 for $24 \mathrm{~h}$, while the control was not treated with any GANT61. The protein profile in the samples was examined by western blot analysis. Briefly, cells were collected and washed three times with PBS. Next, the cells were lysed in fresh radioimmunoprecipitation assay protein lysis buffer containing phenylmethylsulfonyl fluoride (ratio, 100:1) on ice. The total protein concentration was determined by the BCA method (ab102536; Abcam). Following separation by $10 \%$ SDS-PAGE, the samples were transferred to polyvinylidene difluoride films. Protein blots were visualized by Ponceau $\mathrm{S}$ staining. The films were subsequently blocked with $5 \%$ non-fat milk for $2 \mathrm{~h}$ at room temperature. Anti-Gli1 $(1: 500)$ and anti-CyclinD1 $(1: 1,000)$ protein antibodies were added and incubated overnight at $4^{\circ} \mathrm{C}$. The films were then incubated with the secondary antibody $(1: 10,000)$ at room temperature for $1 \mathrm{~h}$ and washed three times with Tris-buffered saline/Tween 20 buffer. An enhanced chemiluminescence reagent (WBKLS0500; Merck Millipore, Billerica, MA, USA) was used to detect the protein levels, which were scanned using a Bio-Rad exposure system, and Image Lab 3.0 software used for quantification (Bio-Rad Laboratories, Inc.).
Immunofluorescence analysis. Daoy cells $\left(5 \times 10^{3}\right)$ were seeded on glass coverslips and treated with different concentrations of GANT61. At $24 \mathrm{~h}$ after incubation, the cells were fixed with $4 \%$ paraformaldehyde for $10 \mathrm{~min}$ and permeabilized with $1 \%$ Triton X-100 in PBS for $10 \mathrm{~min}$. Next, the cells were incubated with rabbit anti-Gli1 and mouse anti-CyclinD1 antibodies at $37^{\circ} \mathrm{C}$ for $1 \mathrm{~h}$ and washed with PBS. Subsequently, incubation for $1 \mathrm{~h}$ with DyLight594-conjugated goat anti-rabbit and FITC conjugated goat anti-mouse secondary antibodies (111-165-003 and 111-025-003; 1:10,000; Jackson ImmunoResearch Laboratories, Inc., West Grove, PA, USA) was performed, followed by DAPI staining. The cells were then mounted and observed under a fluorescence microscope.

Statistical analysis. SPSS version 19.0 (IBM Corp., Armonk, NY, USA) software was used for statistical analysis. Data were statistically analyzed by one-way analysis of variance. All experimental data are expressed as the mean \pm standard deviation. $\mathrm{P}<0.05$ indicated a statistically significant difference.

\section{Results}

Morphological changes of Daoy cells following GANT61 treatment. Daoy cells were cultured for $24 \mathrm{~h}$, and then different concentrations of GANT61 $(10,20$ or $40 \mu \mathrm{M}$ in $0.1 \%$ DMSO) were added to examine the effects of GANT61 on the cell morphology. The cells were cultured for a further $24 \mathrm{~h}$ and then subjected to inverted microscopic observation. As shown in Fig. 1, the normal, non-adherent Daoy cells in the untreated control group were spherical in shape. Similarly, normal adherent cells were intercellular tight, follow flaky 

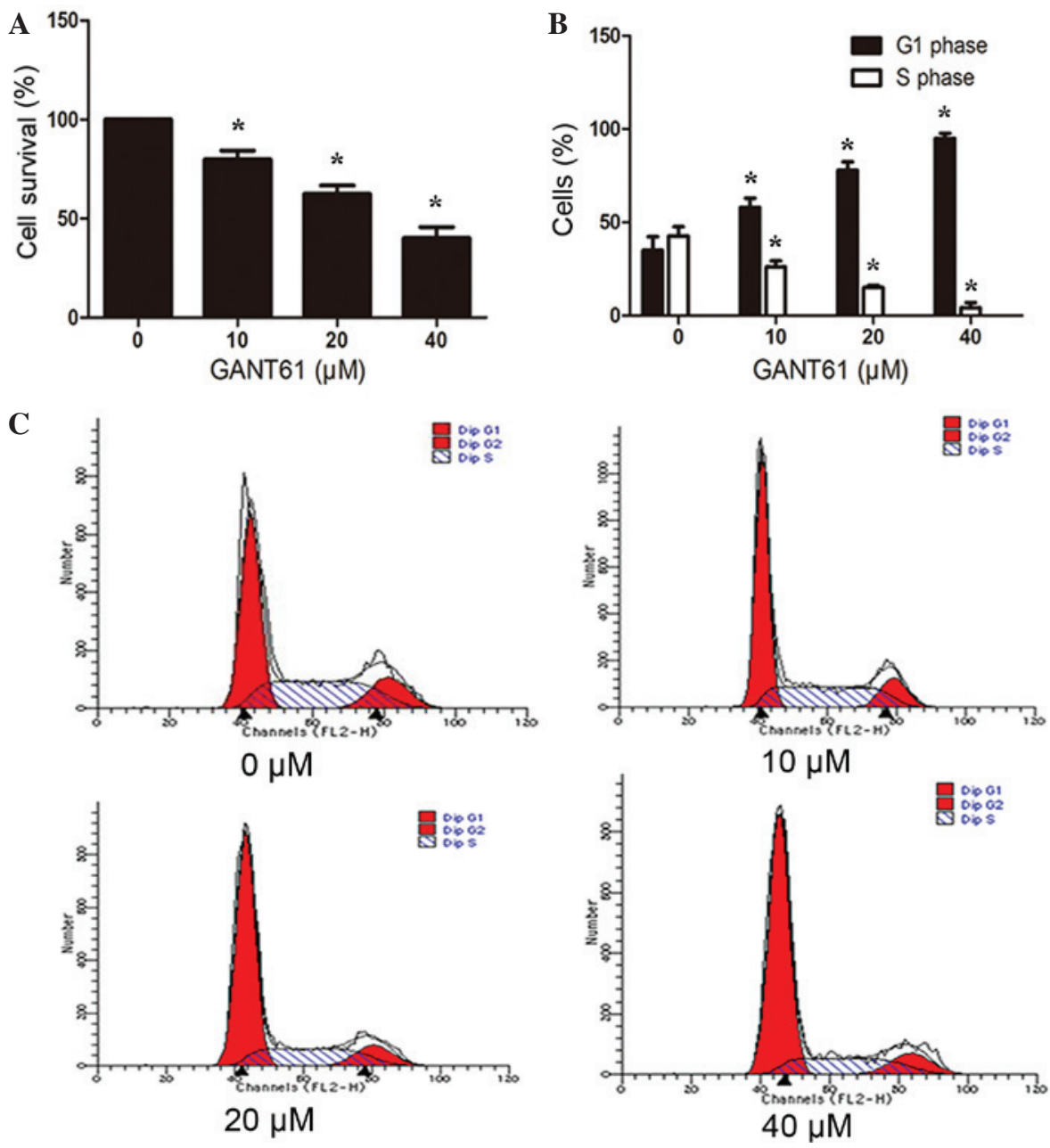

Figure 2. GANT61 inhibits the proliferation of Daoy cells and induces cell cycle arrest. (A) CCK-8 assay was used to investigate the effects of GANT61 treatment for $24 \mathrm{~h}$ on the survival of cells. GANT61 treatment inhibited the cell proliferation in a dose-dependent manner compared with the control group. (B) Percentage of cells at each cell cycle phase and (C) histograms of flow cytometry analysis, which was used to determine the effects of GANT61 treatment $(0-40 \mu \mathrm{M}$ in $0.1 \%$ dimethyl sulfoxide) for $24 \mathrm{~h}$ on cell cycle progression. GANT61 induced G1/S phase arrest of Daoy cells. Results are presented as the mean \pm standard deviation of three independent experiments, and each sample was examined in triplicate $(\mathrm{n}=3)$. ${ }^{*} \mathrm{P}<0.05$ vs. $0 \mu \mathrm{M}$ group. CCK-8, cell counting kit- 8 .

aggregational growth and morphological rules, and their shapes were rectangular or triangular. Notably, groups treated with increasing concentrations of GANT61 demonstrated an evident decreased in cell number, as well as changes in morphology and diversity, which the cells presented with shrinkage and abnormal form. (Fig. 1).

GANT61 inhibits the proliferation and induces cell cycle arrest of Daoy cells. Marked morphological changes and decreased cell number was observed following GANT61 treatment (Fig. 1), indicating reduced cell proliferation or induced cell apoptosis. To elucidate whether cell proliferation was decreased following treatment with different concentrations of GANT61 for $24 \mathrm{~h}$, the cell proliferation was detected by a CCK-8 assay. As shown in Fig. 2A, GANT61 significantly inhibited the proliferation of Daoy cells. The inhibition of proliferation in GANT61-treated groups compared with the control group was dose-dependent ( $\mathrm{P}<0.05$; Fig. 2A). Furthermore, to examine whether the growth inhibition of the cells was a result of cell cycle arrest, Daoy cells were stained with FITC-Annexin V and PI, and then subjected to flow cytometry. As displayed in Fig. 2B and C, the percentage of cells in
G1 phase increased $(\mathrm{P}<0.05)$ with increasing concentration of GANT61 treatment, whereas cells in S phase decreased in a dose-dependent manner $(\mathrm{P}<0.05)$. This indicated that GANT61 resulted in cell cycle arrest of Daoy cells at the G1/S transition.

GANT61 promotes cell apoptosis of Daoy cells. To determine whether GANT61 treatment induced cells apoptosis, normal growing Daoy cells were treated with various concentrations of GANT61. After $24 \mathrm{~h}$, the cells were subjected to HE staining and flow cytometry analysis. As shown in Fig. 3A, the HE staining results demonstrated that normal cells had a regular morphology. However, clearly visible abnormal morphologies were observed in Daoy cells treated with GANT61, with abnormal protuberance observed. The abnormal protuberance, chromatin condensation and fragmentation features were more evident at increased concentrations of GANT61, thus indicating a dose-dependent effect. HE staining also demonstrated decreased in cell number, increased cell shrinkage and nuclear fragmentation. As shown in Fig. 3B, the percentage of apoptotic cells increased significantly in the GANT61-treated cells, compared with the untreated group $(\mathrm{P}<0.05)$. These results 


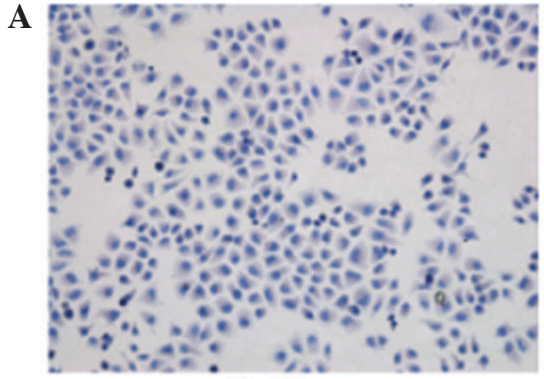

$0 \mu \mathrm{M}$

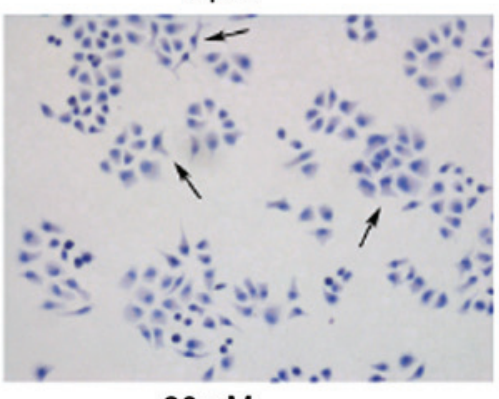

$20 \mu \mathrm{M}$

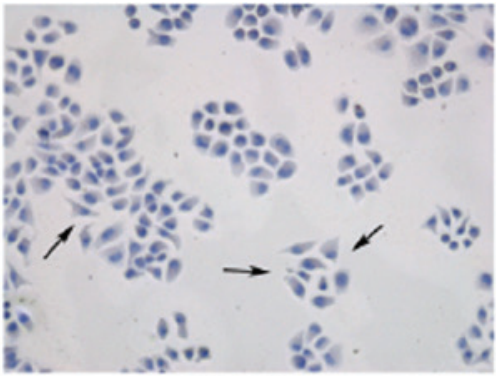

$10 \mu \mathrm{M}$

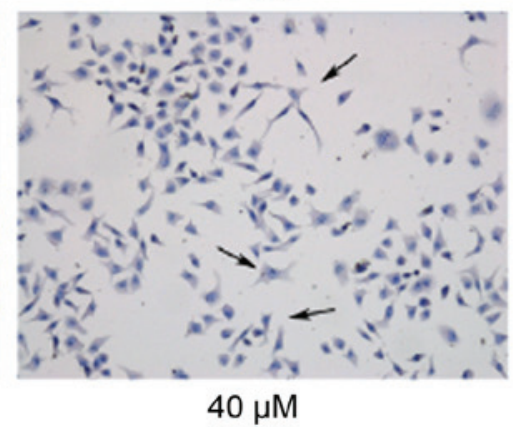

B
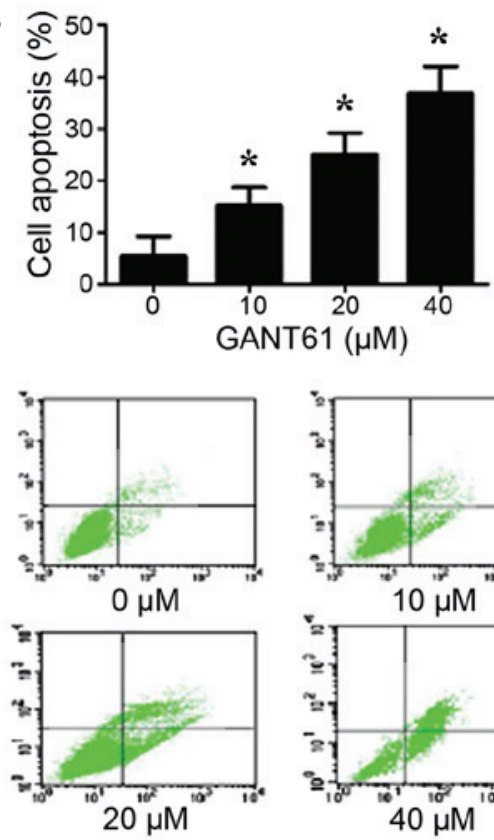
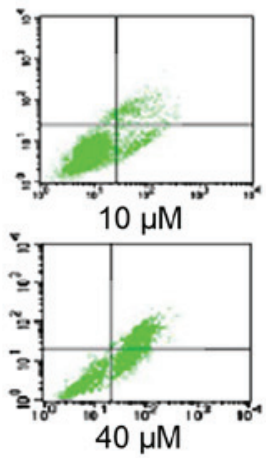

Figure 3. Cell apoptosis induces by GANT61 treatment for $24 \mathrm{~h}$ in Daoy cells. (A) Hematoxylin and eosin staining indicated increased coated abnormal protuberance with increasing concentrations of GANT61 (shown by arrows). (B) FITC-Annexin V flow cytometry analysis showed that GANT61 induced the apoptosis of Daoy cells in a dose-dependent manner. Experiments were performed at least three times ( $\mathrm{n}=3$ ). ${ }^{*} \mathrm{P}<0.05 \mathrm{vs} .0 \mu \mathrm{M}$ group.

verified the prediction that GANT61 induced cell apoptosis in Daoy cells (19).

GANT61 inhibits the expression of Glil and CyclinD1 in the $m R N A$ and protein level. To examine the underlying mechanism of reduced cell apoptosis and cell cycle arrest, the total RNA of the cells were extracted by TRIzol reagent, reverse transcribed into cDNA and then subjected to PCR. Gli1 is an important transcription factor in the $\mathrm{SHH}$ signaling pathway, regulating the transcription of multiple downstream target genes, including CyclinD1, the oncogene controlling cell cycle entry $(22,23)$. As shown in Fig. 4A, the results revealed that GANT61 was able to significantly inhibit the gene expression of Glil $(\mathrm{P}<0.05)$. Along with the decreased expression of the Gli1 gene, CyclinD1 mRNA appeared to be downregulated synchronously $(\mathrm{P}<0.05)$. In addition, protein levels were assayed by immunofluorescence analysis. As indicated in Fig. 4B and C, CyclinD1 was mainly localized in the cytosol of Daoy cells, whereas Gli1, as a transcription factor, was located in both the cell cytosol and nucleus. Following treatment with GANT61 for $24 \mathrm{~h}$, Daoy cells showed decreased levels of Gli1 protein compared with that in untreated cells $(\mathrm{P}<0.05)$. Subsequently, CyclinD1 was also decreased, as one of the Gli1 transcriptional targets $(\mathrm{P}<0.05)$. The inhibition by GANT61 on Gli1 and CyclinD1 was dose-dependent. To further elucidate the inhibitory effects of GANT61 on the expression of Gli1 and CyclinD1, their protein levels were examined by western blot analysis. Daoy cells treated with GANT61 for $24 \mathrm{~h}$ were lysed and separated by SDS-PAGE, and the protein expression levels of Gli1 and CyclinD1 were detected using the corresponding antibodies. The results demonstrated that GANT61 was able to decrease the level of Gli1 protein (Fig. 5). In line with the decreased expression of Gli1 protein, CyclinD1 protein also appeared to be downregulated $(\mathrm{P}<0.05)$. The inhibition of Gli1 and CyclinD1 protein levels by GANT61 was in a dose-dependent manner $(\mathrm{P}<0.05)$. These results were consistent with the data obtained by qPCR and immunofluorescence analyses, indicating that GANT61 can significantly inhibit Gli1 and CyclinD1 expression at the mRNA and protein levels.

\section{Discussion}

Aberrant activation of the SHH signaling pathway is implicated in various types of human cancer (24). The SHH signaling pathway is important in regulating cell proliferation and differentiation in the embryonic development of the cerebellum (25). MB is characterized by constitutive activation of the SHH signaling pathway, and is genetically characterized by mutations in patched homolog 1 (PTCH1), which blocks the function of smoothened (SMO), or other downstream pathway mutations (26). Gli1 expression is inhibited by suppressor-of-fused, preventing it from activating gene transcription. The binding of $\mathrm{SHH}$ to PTCH1 or other mutations releases a basal repression on SMO, which is then activated (27). Subsequently, Gli1 is released and activates a series of gene transcriptions $(28,29)$.

Inhibitors of the $\mathrm{SHH}$ signaling pathway are currently being developed to mainly target SMO or its upstream sites (30). Numerous studies using such inhibitors in MB have demonstrated the efficacy of this treatment, and these findings have been translated into Phase I and II clinical trials (31-34). While these therapies have shown promising results, various significant challenges remain, including the possible long-term bone marrow suppression and drug toxicity $(35,36)$. As the majority of targeted therapies for MB have focused on SMO, it is concerning that only a single mechanism has been identified and targeted, making resistance a frequently encountered complication (37). SMO mutation is not the only mechanism 
A

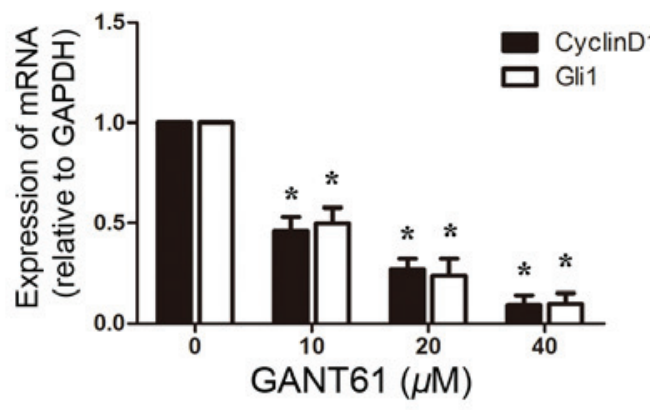

B

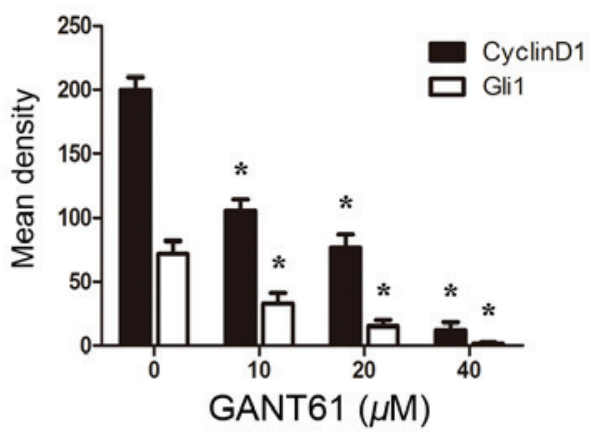

C GANT61 $(\mu \mathrm{M})$

Nucleus

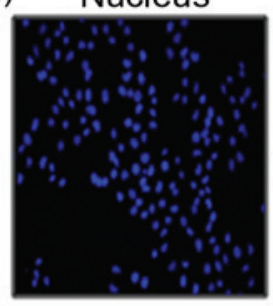

Cyclin D1
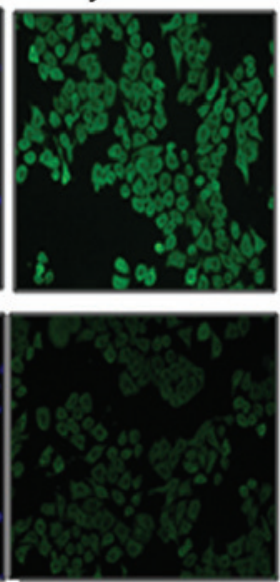

Gli1

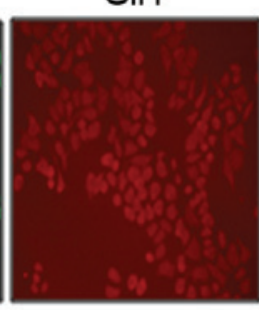

Cyclin D1 Merged
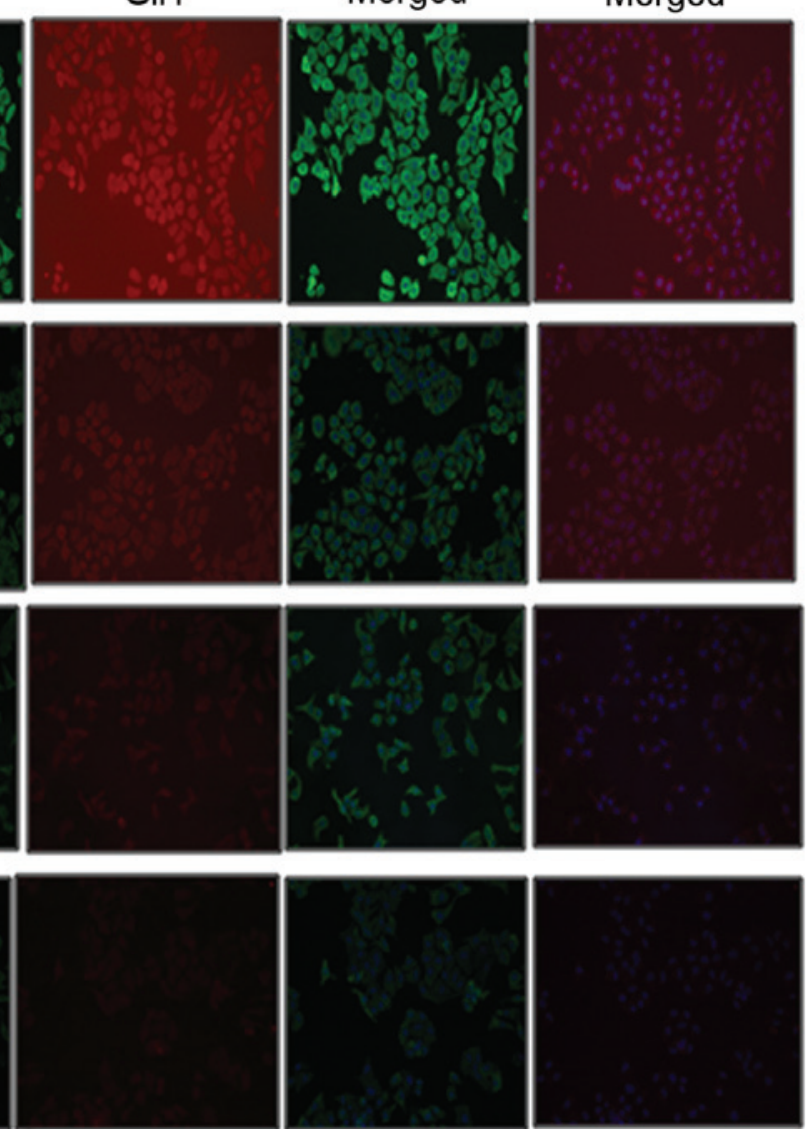
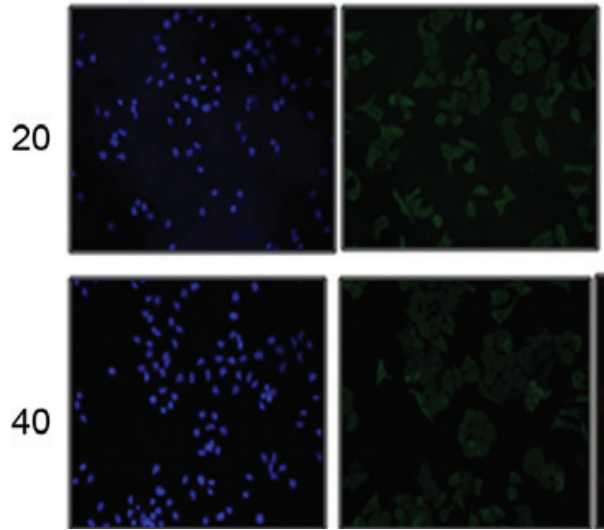

Figure 4. GANT61 inhibits the expression of Gli1 and CyclinD1 in Daoy cells treated with different GANT61 concentrations for $24 \mathrm{~h}$. (A) mRNA expression levels of Gli1 and CyclinD1, as determined by quantitative polymerase chain reaction. Gli1 and CyclinD1 mRNA levels were downregulated following GANT61 treatment, indicating that GANT61 selectively inhibited the SHH signaling pathway at the mRNA level. (B) Mean density and (C) images of immunofluorescence analysis, investigating the protein levels of Gli1 and CyclinD1 to determine the effect of GANT61 treatment on the SHH signaling pathway at protein level. CyclinD1 was mainly localized in the cytosol of Daoy cells, while Gli1 extended to the cell cytosol and nucleus. Gli1 and CyclinD1 were downregulated, and the inhibition was reduced by GANT61 treatment in a dose-dependent manner. ${ }^{*} \mathrm{P}<0.05$ vs. $0 \mu \mathrm{M}$ group. Analyses were performed at least in triplicate for each experiment (n=3). SHH, sonic hedgehog; Gli1, Gli family zinc finger 1 .
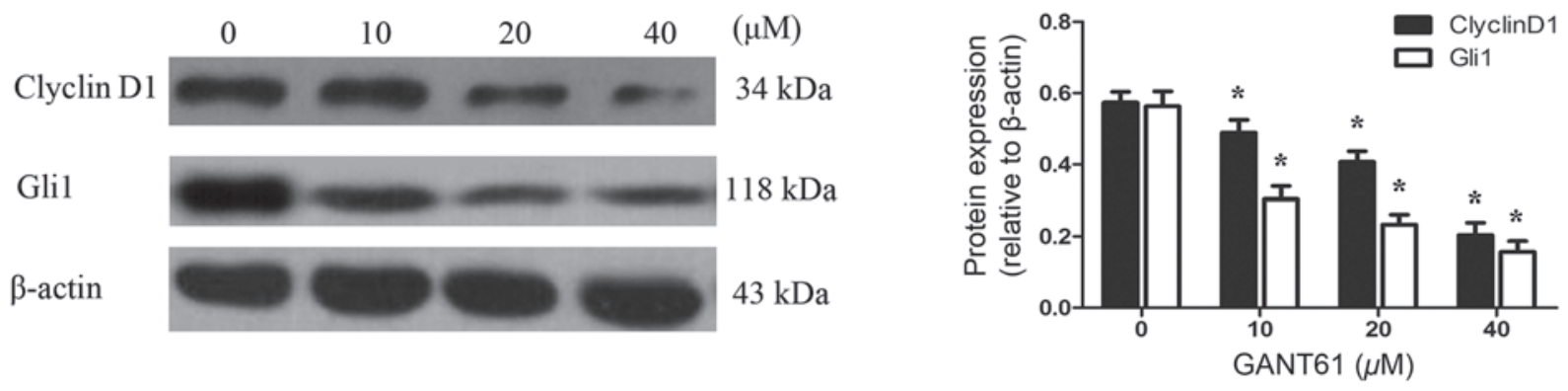

Figure 5. GANT61 selectively inhibits SHH signaling pathway at the protein level, as determined by western blot analysis. Gli1 and CyclinD1 were downregulated by GANT61 treatment. Analyses were performed at least in triplicate for each experiment $(\mathrm{n}=3)$. ${ }^{*} \mathrm{P}<0.05 \mathrm{vs} .0 \mu \mathrm{M}$ group. SHH, sonic hedgehog; Gli1, Gli family zinc finger 1. 
of acquired drug resistance, as the development of other downstream hedgehog pathway component mutations have since been implicated in $\mathrm{SHH}$ inhibitor resistance. Kool et al (38) indicated that amplifications of Gli may result in inability to respond to current SMO inhibitors. Such aberrations include the amplification of Gli and the upregulation of PI3K/AKT signaling, manifesting in vivo as tumor regrowth in the same mouse model $(39,40)$.

Gli1 serves a crucial role in the transformation and proliferation of malignant cells (41). It is also important for preventing apoptosis and maintaining the malignant proliferation of tumor cells, and is involved in tumor cell protection against chemotherapy (42). Berman et al (43) indicated that the expression level of Gli1 may reflect the degree of activation of the SHH signaling pathway. Inhibition of abnormal activation of this signaling pathway by inhibiting the expression of Gli1 can inhibit the growth of tumor cells. Gli1, as the main transcription factor downstream of the SHH signaling pathway, may be able to inhibit tumor cell proliferation and differentiation through downregulation of downstream target genes. On the basis of the pivotal role of Glil in malignant cells, it has become increasingly evident that Gli1 is a promising target for anticancer therapy. A direct strategy to interfere with Gli1 activity is to induce selective inhibition of its DNA transcription.

GANT61, an agent that exerts an inhibitory activity of the SHH signaling pathway, functions by selectively binding to Gli1 and has been found to suppress proliferation in various tumors $(44,45)$. In the present study, GANT61 had in vitro activity against tumor proliferation, and induced cell cycle arrest and apoptosis. Furthermore, GANT61 was found to inhibit the Gli1 mRNA and protein expression levels. Dysregulation of cell cycle progression is considered to serve an important role in cancer; thus, the current study investigated whether Gli1 is associated with the typical oncogene CyclinD1 in the cell cycle. CyclinD1 is a key protein regulating the G1/S transition in the cell cycle and is highly expressed in multiple types of tumors (46). CyclinD1 is frequently deregulated in various cancer types, and is a biomarker of cancer phenotype and disease progression $(46,47)$. Overexpressed CyclinD1 accelerates the cell cycle transition, leading to uncontrolled cell proliferation and the development of cancer. The present study identified that the mRNA expression of Gli1 was significantly associated with CyclinD1 expression in MB, and a similar observation was identified regarding the protein levels. Suppressing the expression of Gli1 may inhibit the overexpression of CyclinD1 and the proliferation of tumor cells, and synchronously promote cell apoptosis. Therefore, blocking the expression of Gli1 may be an attractive therapeutic strategy for MB.

In conclusion, $\mathrm{SHH}$ signaling pathway can regulate tumor cell cycle and apoptosis in different molecular levels. Increased expression of Gli1 induced the upregulation of CyclinD1 expression, thus promoting cell proliferation, which may be one of the growth patterns of tumor cells. Therefore, Gli1 may be an important target for MB treatment. Therapies using Gli1-targeted inhibitors alone or combined with other cytotoxic chemotherapeutics may become an effective targeted treatment of MB. However, the association of the SHH signaling pathway and other pathways in MB cells with the specific mechanism of apoptosis induced by targeted therapy requires further investigation.

\section{Acknowledgements}

The present study was supported by grants from the Natural Science Foundation of Zhejiang Province (no. LY13H160033), the Zhejiang Medical and Health Science and Technology Plan Project (no. 2012RCA043) and the Foundation of Wenzhou Scientific and Technological Bureau Project (no. Y20160031 and no. Y20140717).

\section{References}

1. Gerber NU, Mynarek M, von Hoff K, Friedrich C, Resch A and Rutkowski S: Recent developments and current concepts in medulloblastoma. Cancer Treat Rev 40: 356-365, 2014.

2. Gilbertson RJ: Medulloblastoma: Signalling a change in treatment. Lancet Oncol 5: 209-218, 2004.

3. Packer RJ and Vezina G: Management of and prognosis with medulloblastoma: Therapy at a crossroads. Arch Neurol 65: 1419-1424, 2008.

4. Rutkowski S, von Hoff K, Emser A, Zwiener I, Pietsch T, Figarella-Branger D, Giangaspero F, Ellison DW, Garre ML, Biassoni V, et al: Survival and prognostic factors of early childhood medulloblastoma: An international meta-analysis. J Clin Oncol 28: 4961-4968, 2010.

5. Moxon-Emre I, Bouffet E, Taylor MD, Laperriere N, Scantlebury N, Law N, Spiegler BJ, Malkin D, Janzen L and Mabbott D: Impact of craniospinal dose, boost volume, and neurologic complications on intellectual outcome in patients with medulloblastoma. J Clin Oncol 32: 1760-1768, 2014.

6. Archer TC, Weeraratne SD and Pomeroy SL: Hedgehog-GLI pathway in medulloblastoma. J Clin Oncol 30: 2154-2156, 2012.

7. Gotschel F, Berg D, Gruber W, Bender C, Eberl M, Friedel M, Sonntag J, Rüngeler E, Hache H, Wierling C, et al: Synergism between Hedgehog-GLI and EGFR signaling in Hedgehog-responsive human medulloblastoma cells induces downregulation of canonical Hedgehog-target genes and stabilized expression of GLI1. PLoS One 8: e65403, 2013.

8. Cho YJ, Tsherniak A, Tamayo P, Santagata S, Ligon A, Greulich H, Berhoukim R, Amani V, Goumnerova L, Eberhart CG, et al: Integrative genomic analysis of medulloblastoma identifies a molecular subgroup that drives poor clinical outcome. J Clin Oncol 29: 1424-1430, 2011.

9. Mcmillan R and Matsui W: Molecular pathways: The hedgehog signaling pathway in cancer. Clin Cancer Res 18: 4883-4888, 2012.

10. Shahi MH, Afzal M, Sinha S, Eberhart CG, Rey JA, Fan X and Castresana JS: Regulation of sonic hedgehog-GLI1 downstream target genes PTCH1, Cyclin D2, Plakoglobin, PAX6 and NKX2.2 and their epigenetic status in medulloblastoma and astrocytoma. BMC Cancer 10: 614, 2010.

11. Kenney AM, Cole MD and Rowitch DH: Nmyc upregulation by sonic hedgehog signaling promotes proliferation in developing cerebellar granule neuron precursors. Development 130: 15-28, 2003.

12. Musgrove EA, Caldon CE, Barraclough J, Stone A and Sutherland RL: Cyclin D as a therapeutic target in cancer. Nat Rev Cancer 11: 558-572, 2011.

13. Barbash O, Zamfirova P, Lin DI, Chen X, Yang K, Nakagawa H, Lu F, Rustgi AK and Diehl JA: Mutations in Fbx4 inhibit dimerization of the SCF (Fbx4) ligase and contribute to cyclin D1 overexpression in human cancer. Cancer Cell 14: 68-78, 2008.

14. Fu M, Wang C, Li Z, Sakamaki T and Pestell RG: Minireview: Cyclin D1: Normal and abnormal functions. Endocrinology 145: 5439-5447, 2004

15. Musgrove EA: Cyclins: Roles in mitogenic signaling and oncogenic transformation. Growth Factors 24: 13-19, 2006.

16. Fu J, Rodova M, Roy SK, Sharma J, Singh KP, Srivastava RK and Shankar S: GANT-61 inhibits pancreatic cancer stem cell growth in vitro and in NOD/SCID/IL2R gamma null mice xenograft. Cancer Lett 330: 22-32, 2013.

17. Peukert S and Miller-Moslin K: Small-molecule inhibitors of the hedgehog signaling pathway as cancer therapeutics. ChemMedChem 5: 500-512, 2010.

18. Mazumdar T, Devecchio J, Shi T, Jones J, Agyeman A and Houghton JA: Hedgehog signaling drives cellular survival in human colon carcinoma cells. Cancer Res 71: 1092-1102, 2011. 
19. Lin Z, Li S, Sheng H, Cai M, Ma LY, Hu L, Xu S, Yu LS and Zhang N: Suppression of GLI sensitizes medulloblastoma cells to mitochondria-mediated apoptosis. J Cancer Res Clin Oncol 142: 2469-2478, 2016.

20. Rafiee M, Keramati MR, Ayatollahi H, Sadeghian MH, Barzegar M, Asgharzadeh A and Alinejad M: Down-Regulation of Ribosomal S6 kinase RPS6KA6 in Acute Myeloid Leukemia Patients. Cell J 18: 159-164, 2016.

21. Floris I, Billard H, Boquien CY, Joram-Gauvard E, Simon L, Legrand A, Boscher C, Rozé JC, Bolaños-Jiménez F and Kaeffer B: MiRNA Analysis by Quantitative PCR in Preterm Human Breast Milk Reveals Daily Fluctuations of hsa-miR-16-5p. PLoS One 10: e140488, 2015.

22. Huang XB, Shi Y, Wang CS, Wang XD, Cheng J and Che FF: Synergistic Inhibitory Effect of Arsenic Trioxide Combined with Itraconazole on Hedgehog Pathway of Multiple Myeloma NCI-H929 Cells. Zhongguo Shi Yan Xue Ye Xue Za Zhi 24: 1459-1465, 2016 (In Chinese).

23. Du WZ, Feng Y, Wang XF, Piao XY, Cui YQ, Chen LC, Lei XH, Sun X, Liu X, Wang HB, et al: Curcumin suppresses malignant glioma cells growth and induces apoptosis by inhibition of SHH/GLI1 signaling pathway in vitro and vivo. CNS Neurosci Ther 19: 926-936, 2013

24. Nakamura $M$ and Katano $M$ : Hedgehog signaling pathway and its impact on development of cancer therapy. Fukuoka Igaku Zasshi 99: 102-106, 2008 (In Japanese).

25. Malek R, Matta J, Taylor N, Perry ME and Mendrysa SM: The p53 inhibitor MDM2 facilitates Sonic Hedgehog-mediated tumorigenesis and influences cerebellar foliation. PLoS One 6: e17884, 2011.

26. Sahebjam S, Siu LL and Razak AA: The utility of hedgehog signaling pathway inhibition for cancer. Oncologist 17: 1090-1099, 2012.

27. Wang X, Venugopal C, Manoranjan B, McFarlane N, O'Farrell E, Nolte S, Gunnarsson T, Hollenberg R, Kwiecien J, Northcott P, et al: Sonic hedgehog regulates Bmil in human medulloblastoma brain tumor-initiating cells. Oncogene 31: 187-199, 2012.

28. Jiang J and Hui CC: Hedgehog signaling in development and cancer. Dev Cell 15: 801-812, 2008.

29. Ruiz i Altaba A, Palma V and Dahmane N: Hedgehog-Gli signalling and the growth of the brain. Nat Rev Neurosci 3: 24-33, 2002.

30. Tang Y, Gholamin S, Schubert S, Willardson MI, Lee A, Bandopadhayay P, Bergthold G, Masoud S, Nguyen B, Vue N, et al: Epigenetic targeting of Hedgehog pathway transcriptional output through BET bromodomain inhibition. Nat Med 20: 732-740, 2014

31. Jimeno A, Weiss GJ, Miller WH Jr, Gettinger S, Eigl BJ, Chang AL, Dunbar J, Devens S, Faia K, Skliris G, et al: Phase I study of the Hedgehog pathway inhibitor IPI-926 in adult patients with solid tumors. Clin Cancer Res 19: 2766-2774, 2013.

32. Berlin J, Bendell JC, Hart LL, Firdaus I, Gore I, Hermann RC, Mulcahy MF, Zalupski MM, Mackey HM, Yauch RL, et al: A randomized phase II trial of vismodegib versus placebo with FOLFOX or FOLFIRI and bevacizumab in patients with previously untreated metastatic colorectal cancer. Clin Cancer Res 19: 258-267, 2013.

33. Kim EJ, Sahai V, Abel EV, Griffith KA, Greenson JK, Takebe N, Khan GN, Blau JL, Craig R, Balis UG, et al: Pilot clinical trial of hedgehog pathway inhibitor GDC-0449 (vismodegib) in combination with gemcitabine in patients with metastatic pancreatic adenocarcinoma. Clin Cancer Res 20: 5937-5945, 2014.
34. D'Amato C, Rosa R, Marciano R, D'Amato V, Formisano L, Nappi L, Raimondo L, Di Mauro C, Servetto A, Fulciniti F, et al: Inhibition of Hedgehog signalling by NVP-LDE225 (Erismodegib) interferes with growth and invasion of human renal cell carcinoma cells. Br J Cancer 111: 1168-1179, 2014.

35. Rudin CM, Hann CL, Laterra J, Yauch RL, Callahan CA, Fu L, Holcomb T, Stinson J, Gould SE, Coleman B, et al: Treatment of medulloblastoma with hedgehog pathway inhibitor GDC-0449. N Engl J Med 361: 1173-1178, 2009.

36. Kimura H, Ng JM and Curran T: Transient inhibition of the Hedgehog pathway in young mice causes permanent defects in bone structure. Cancer Cell 13: 249-260, 2008.

37. Meani RE, Lim SW, Chang AL and Kelly JW: Emergence of chemoresistance in a metastatic basal cell carcinoma patient after complete response to hedgehog pathway inhibitor vismodegib (GDC-0449). Australas J Dermatol 55: 218-221, 2014.

38. Kool M, Jones DT, Jäger N, Northcott PA, Pugh TJ, Hovestadt V, Piro RM, Esparza LA, Markant SL, Remke M, et al: Genome sequencing of SHH medulloblastoma predicts genotype-related response to smoothened inhibition. Cancer Cell 25: 393-405, 2014.

39. Samkari A, White J and Packer R: SHH inhibitors for the treatment of medulloblastoma. Expert Rev Neurother 15: 763-770, 2015.

40. Pan S, Wu X, Jiang J, Gao W, Wan Y, Cheng D, Han D, Liu J, Englund NP, Wang Y, et al: Discovery of NVP-LDE225, a potent and selective smoothened antagonist. ACS Med Chem Lett 1: 130-134, 2010.

41. Ruiz i Altaba A, Mas C and Stecca B: The Gli code: An information nexus regulating cell fate, stemness and cancer. Trends Cell Biol 17: 438-447, 2007.

42. Katoh Y and Katoh M: Hedgehog target genes: Mechanisms of carcinogenesis induced by aberrant hedgehog signaling activation. Curr Mol Med 9: 873-886, 2009.

43. Berman DM, Karhadkar SS, Hallahan AR, Pritchard JI, Eberhart CG, Watkins DN, Chen JK, Cooper MK, Taipale J, Olson JM and Beachy PA: Medulloblastoma growth inhibition by hedgehog pathway blockade. Science 297: 1559-1561, 2002.

44. Miyazaki Y, Matsubara S, Ding Q, Tsukasa K, Yoshimitsu M, Kosai $\mathrm{K}$ and Takao S: Efficient elimination of pancreatic cancer stem cells by hedgehog/GLI inhibitor GANT61 in combination with mTOR inhibition. Mol Cancer 15: 49, 2016.

45. Benvenuto M, Masuelli L, De Smaele E, Fantini M, Mattera R, Cucchi D, Bonanno E, Di Stefano E, Frajese GV, Orlandi A, et al: In vitro and in vivo inhibition of breast cancer cell growth by targeting the Hedgehog/GLI pathway with SMO (GDC-0449) or GLI (GANT-61) inhibitors. Oncotarget 7: 9250-9270, 2016.

46. Li X, Hao Z, Fan R, Zou X, Jin H, Pan Y, He L, Du R, Gao L, Liu D and Fan D: CIAPIN1 inhibits gastric cancer cell proliferation and cell cycle progression by downregulating CyclinD1 and upregulating P27. Cancer Biol Ther 6: 1539-1545, 2007.

47. Seiler R, Thalmann GN, Rotzer D, Perren A and Fleischmann A: CCND1/CyclinD1 status in metastasizing bladder cancer: A prognosticator and predictor of chemotherapeutic response. Mod Pathol 27: 87-95, 2014. 